Article

\title{
Equivalent Circuit Models for Determination of the Relation between the Sensing Behavior and Properties of Undoped/Cr Doped $\mathrm{TiO}_{2}$ NTs
}

\author{
Yakup Gönüllü ${ }^{1,2}$, Klemens Kelm ${ }^{1}$, Sanjay Mathur ${ }^{2}$ and Bilge Saruhan ${ }^{1}{ }^{*}$ \\ 1 German Aerospace Center (DLR), Institute of Materials Research, 51147 Cologne, Germany; \\ E-Mail: klemens.kelm@dlr.de \\ 2 University of Cologne, Institute of Inorganic Chemistry, 50939 Cologne, Germany; \\ E-Mails: y.goenuellue@uni-koeln.de (Y.G.); sanjay.mathur@uni-koeln.de (S.M.) \\ * Author to whom correspondence should be addressed; E-Mail: bilge.saruhan@ dlr.de; \\ Tel.: +49-2203-601-3228.
}

Received: 15 December 2013; in revised form: 15 January 2014 / Accepted: 29 January 2014 / Published: 20 February 2014

\begin{abstract}
High-temperature gas sensing requires the increase of sensitivity and reduction of cross-sensitivity. The use of $\mathrm{TiO}_{2}$-Nanotubular layers as gas sensors has shown that the selectivity and sensitivity can be influenced by doping with trivalent elements and by optimization of morphological aspects such as pore diameter and nanotube length. In this work, focus has been given on the understanding of the effect of doping and properties of nano-tubular $\mathrm{TiO}_{2}$-layers on sensing behavior and mechanism toward $\mathrm{NO}_{2}$ by using equivalent circuit modeling achieved by impedance spectroscopic measurements.
\end{abstract}

Keywords: $\mathrm{Cr}$ doping; $\mathrm{TiO}_{2}$ Nanotubes; gas sensors; equivalent circuit model

\section{Introduction}

The increasing concern in the detection of combustion gases calls for the development of highly sensitive sensor devices as well as for the understanding and determination of simplified models of sensor operation mechanisms. The interest has been focused in wide band-gap semiconducting metal oxides such as $\mathrm{SnO}_{2}, \mathrm{ZnO}$ and $\mathrm{TiO}_{2}$, which suffer changes in the conductance when oxidizing or reducing species in air chemisorb onto the oxide particle or film surface [1]. Bulk undoped and doped $\mathrm{TiO}_{2}$ layers have been used as gas sensors for years [1,2]. However, sensors based on $\mathrm{TiO}_{2}$ systems 
require more efforts in order to improve the selectivity, stability and response times at high temperature $\left(300{ }^{\circ} \mathrm{C}-600{ }^{\circ} \mathrm{C}\right)[3,4]$. One of the suggested methods for improving the performance of such sensors is doping of $\mathrm{TiO}_{2}$ based systems with trivalent elements such as $\mathrm{Al}, \mathrm{Pt}, \mathrm{Cr}$, etc. [5-7]. Absorption and diffusion driven sensing, as in the case of gas sensors, is generally related with the directly accessible surface area. Thus, a favorite solution for the achievement of higher performance at gas sensors has been to increase the surface area of the sensing electrodes by micro- or nano-scale structuring [1]. Relying on high specific surface area, the miniaturized gas sensors having $\mathrm{TiO}_{2}$ nanotubular (NTs) sensing electrodes have advantages and became the topic for many recent publications. In a recent review article by D. Kim and co-workers [2], the author emphases the importance of surface area and porosity even in the semi-conductive oxides for gas sensing with the following lines: Bulk transport properties of sensor layers, for example semi-conductive oxides, require an understanding of both solid-state physics and defect thermodynamics and kinetics. The chemisorption of molecular and atomic species on the surface of such semiconductors relies on charge transfer processes. Simplicity and high sensitivity of these devices based on SMO (Semiconducting Metal Oxide) and chemisorption are achieved by the advent of nanostructured materials, possessing high surface area, high porosity and effective surface depletion modulation. It has already been demonstrated that $\mathrm{TiO}_{2}$ NTs based sensors exhibit excellent gas sensing properties towards $\mathrm{H}_{2}[3,4]$ and $\mathrm{NO}_{2}$ at a temperature range of $300{ }^{\circ} \mathrm{C}-500{ }^{\circ} \mathrm{C}$ [5]. On the other hand, the selectivity of the $\mathrm{TiO}_{2}$ NTs based sensors towards $\mathrm{NO}_{2}$ at these intermediate temperatures displays a poor characteristic. In a following work, it has been reported that $\mathrm{Cr}$ doping of $\mathrm{TiO}_{2} \mathrm{NT}$ could increase the $\mathrm{NO}_{2}$-selectivity in $\mathrm{NO}_{2}+\mathrm{CO}$ mixed test gas ambient yielding higher response towards $\mathrm{NO}_{2}$ at a moderate temperature range (i.e., $300{ }^{\circ} \mathrm{C}$ to $500{ }^{\circ} \mathrm{C}$ ) [6]. Although there are reports in the literature demonstrating the achieved improvements by and importance of nano-structuring in the case of $\mathrm{TiO}_{2}$, nevertheless, the reasons for the effect of morphology, the layer thickness and Cr-doping of $\mathrm{TiO}_{2} \mathrm{NTs}$ on gas sensing have been rarely investigated. This work describes the fabrication of $\mathrm{TiO}_{2} \mathrm{NTs}$ sensor layers through anodization of titanium substrates as well as an effective doping process of introducing trivalent chromium into the $\mathrm{TiO}_{2}$ NTs layers. Moreover, it reports the effect of microstructural parameters (i.e., thickness and tubular diameter) on sensor behavior using the impedance response and equivalent circuit models (fitting technique) at various temperatures $\left(300{ }^{\circ} \mathrm{C}-500{ }^{\circ} \mathrm{C}\right)$.

\section{Experimental Methods}

\subsection{Synthesis of Undoped and Doped $\mathrm{TiO}_{2} \mathrm{NTS}$}

Self-organized $\mathrm{TiO}_{2}$ NTs were synthesized by anodization of pure titanium substrates. Before starting the anodization process, the titanium substrates were mirror polished. The Ti-foils were rinsed with the de-ionized water and cleaned in an ultrasonic bath after every polishing step. The anodization of titanium substrates was carried out at room temperature (RT) in an Ethylene Glycol (EG) based electrolyte under continuous magnetic stirring, as previously reported [5]. A platinum foil was used as a cathode during the anodization process. The distance of titanium platinum was kept constant (e.g., $20 \mathrm{~mm}$ ) for all anodization processes. After the anodization of Ti substrates, the samples were rinsed with ethanol and dried in air prior to the characterization. The $\mathrm{TiO}_{2} \mathrm{NTs}$ samples, which were used without doping, were annealed at $700{ }^{\circ} \mathrm{C}$ for $3 \mathrm{~h}$ in atmospheric air in order to obtain well-crystallized 
$\mathrm{TiO}_{2}$ NTs. It is important to note that the samples, which were used for $\mathrm{Cr}$ doping process, were not annealed directly after anodization process. The $\mathrm{Cr}$ doping was achieved by means of a sol-dipping process. The $1 \mathrm{M} \mathrm{Cr}^{3+}$-solution was prepared by dissolving $\mathrm{Cr}\left(\mathrm{NO}_{3}\right)_{3} * 9 \mathrm{H}_{2} \mathrm{O}$ in distilled water. The as anodized $\mathrm{TiO}_{2}$ NTs were dipped into $\mathrm{Cr}\left(\mathrm{NO}_{3}\right)_{3} * 9 \mathrm{H}_{2} \mathrm{O}$ solution in a vacuum desiccator for $5 \mathrm{~h}$. Vacuum atmosphere was required in order to eliminate the air trapped in $\mathrm{TiO}_{2} \mathrm{NTs}_{\text {s }}$ through which the infiltration of $\mathrm{Cr}^{3+}$-solution could be inhibited from reaching to the bottom of $\mathrm{TiO}_{2} \mathrm{NTs}$. For incorporation of $\mathrm{Cr}^{3+}$ in to the $\mathrm{TiO}_{2}$-lattice, the soaked NTs were annealed at various temperatures from $400{ }^{\circ} \mathrm{C}$ to $700{ }^{\circ} \mathrm{C}$ for $3 \mathrm{~h}$ in order to obtain the crystalline phases of $\mathrm{TiO}_{2}$, which is in this case anatase.

\subsection{Characterization of Microstructure, Phase Condition}

A scanning electron microscope (SEM) (Ultra 55 from ZEISS) equipped with an Energy Dispersive $\mathrm{X}$-ray (EDX) analyzer was employed for the investigation of the obtained morphology including the diameter and length of the nano-tubular layer and the changes in the morphology, which may occur in case of doping and/or heat treatment. A detailed investigation of the morphology and composition of the doped layers was carried out by transmission electron microscope (TEM). In addition, TEM investigations by means of bright/dark field were employed to determine the phase conditions of the $\mathrm{Cr}$ doped $\mathrm{TiO}_{2}$ NTs. The phase analysis of all samples (undoped and doped $\mathrm{TiO}_{2} \mathrm{NTs}$ ) were carried out by X-ray diffraction measurements (XRD) at D5000 using a SIEMENS powder diffractometer by employing $\mathrm{Cu} \mathrm{K} \alpha$ radiation $(\lambda=1.54056 \AA)$ and using an acceleration voltage of $40 \mathrm{kV}$.

\subsection{DC-Resistance Measurements of Undoped and Doped $\mathrm{TiO}_{2} \mathrm{NTs}$}

The gas sensing properties of the undoped and doped $\mathrm{TiO}_{2} \mathrm{NTs}$ were monitored by means of DC resistance measurements, with a 2635 A Source-meter from Keithley. Two parallel platinum circuits with $2 \mathrm{~mm}$ interspace were deposited on the sensing layers by sputtering technique. Figure 1 illustrates the schematic of the $\mathrm{TiO}_{2}$ NTs with platinum electrodes for gas sensing experiments. The gas sensing measurements of the undoped and doped $\mathrm{TiO}_{2} \mathrm{NTs}$ were carried out at $300{ }^{\circ} \mathrm{C}$ to $500{ }^{\circ} \mathrm{C}$ in a gas-release reactor placed inside a tubular Carbolite furnace.

\subsection{AC-Impedance Measurements of $\mathrm{TiO}_{2} \mathrm{NTs}$}

Impedance spectra were recorded from 0.001 up to $1 \mathrm{MHz}$ with no bias and limited voltage $(100 \mathrm{mV})$ as pre-heated gas mixture was contacting with sensor samples. Different potentials (25, 50, 100 and $250 \mathrm{mV}$ ) were applied during the impedance measurements. However, $\mathrm{TiO}_{2} \mathrm{NTs}_{\text {save showed }}$ only a regular response at $100 \mathrm{mV}$ while $\mathrm{Cr}$ doped samples have showed a regular response for all applied potentials. Thus, the applied potential kept constant at $100 \mathrm{mV}$ during the measurements. The spectra analysis, the equivalent circuit (EC) and the simulation of the EC were done with the software ZView of Scribner Assoc., which applies a modified CNLS-fit. 
Figure 1. Schematic of nano-tubular sensor layers.

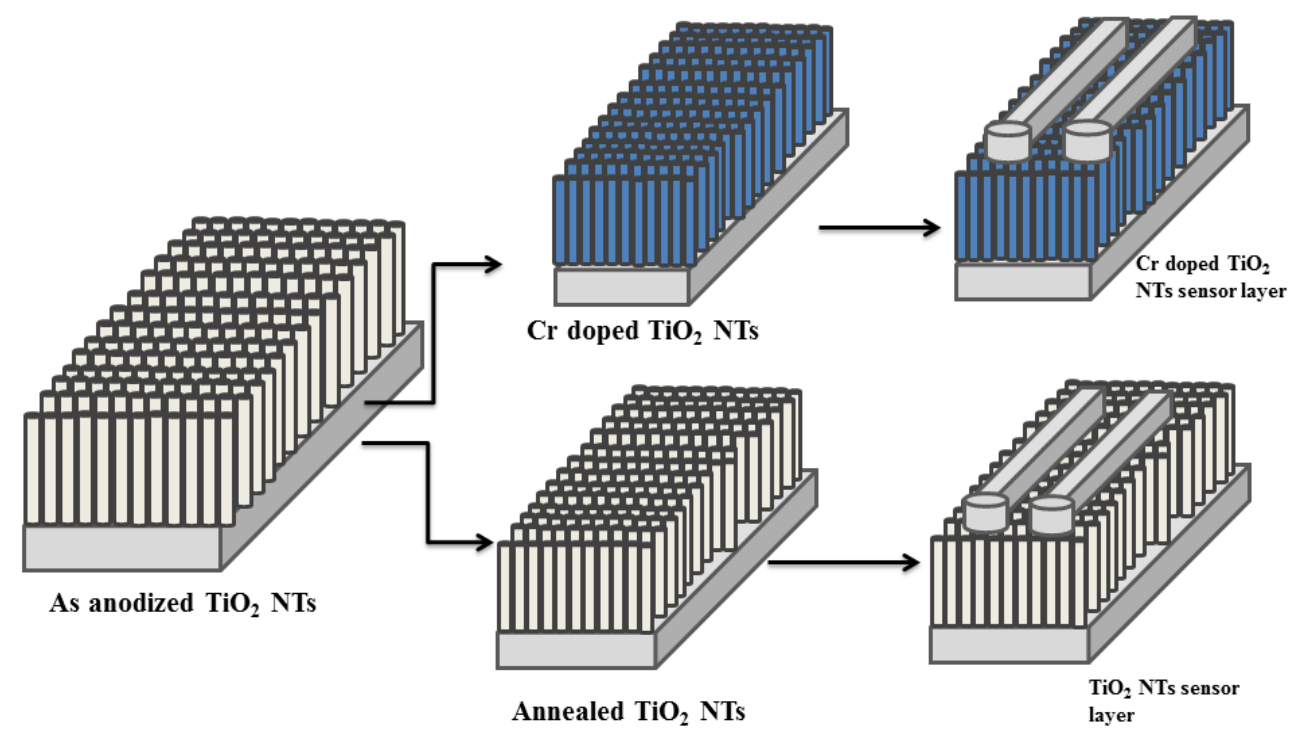

\section{Results and Discussions}

\subsection{Morphology of $\mathrm{TiO}_{2} \mathrm{NTs}$}

Figure 2 exhibits the thickness evolution of the $\mathrm{TiO}_{2}$ NTs with time during anodization in EG-based electrolyte. Thickness of the $\mathrm{TiO}_{2}$ NTs increases linearly with the anodization time. The growth of the $\mathrm{TiO}_{2}$ NTs starts with the formation of a porous oxide layer and approximately at the end of $30 \mathrm{~min}$, well-ordered nanotubular layers appears underneath of a porous layer (see Figure 2a,b).

Figure 2. (a) Top-view and (b) cross-section SEM micrographs of $\mathrm{TiO}_{2} \mathrm{NTs}$ in Ethylene Glycol (EG) based solution under an applied voltage of $60 \mathrm{~V}$ for different anodization times.
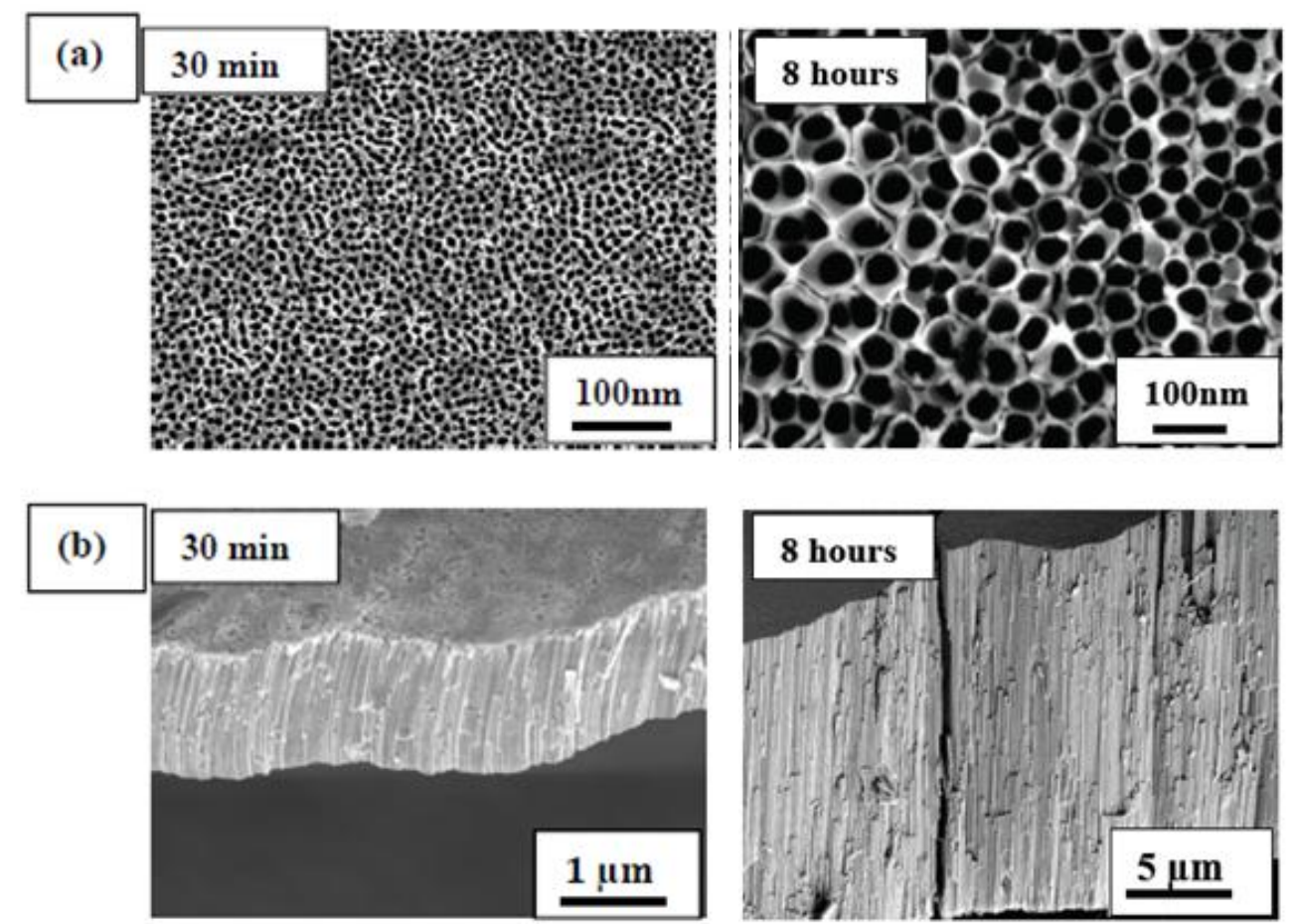
A continuous anodization in EG-based electrolyte for duration of $3 \mathrm{~h}$ leads to not only an increase in the thickness of $\mathrm{TiO}_{2} \mathrm{NTs}$ but also results in a thinner outer initial layer. In this case, no oxide layer covering the top mouths $\mathrm{TiO}_{2}$ NTs has been observed. The top of the $\mathrm{TiO}_{2}$ NTs starts to connect in bunches.

A further extension of the anodization time over $10 \mathrm{~h}$ did not make any significant change in the diameter (see Figure 3). It appears that the diameter evolution reaches to a limit after 3 to $4 \mathrm{~h}$ of anodization (approx. $\cong 95 \mathrm{~nm}$ ). The stabilization in diameter change is due to the achievement of a steady-state condition between the formation of NTs and dissolution of the oxide layers. On the other hand, a steady increase of the layer thickness has been observed with the anodization duration. According to these observations, after $10 \mathrm{~h}$ of anodization, NTs layers as thick as $55 \mu \mathrm{m}$ are achievable in EG-based electrolytes. Although various layer thicknesses were employed for the impedance tests,

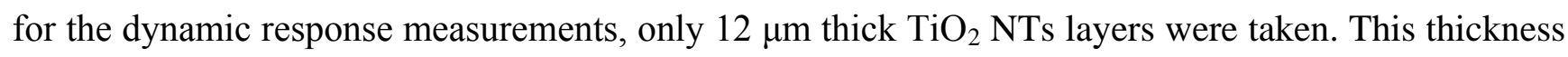
was chosen according to the pre-characterization tests and details are given in the Section 3.3.1.

Figure 3. Measured layer thickness and surface diameter of the obtained $\mathrm{TiO}_{2} \mathrm{NTs}$ in EG-based solutions depending on anodization time.

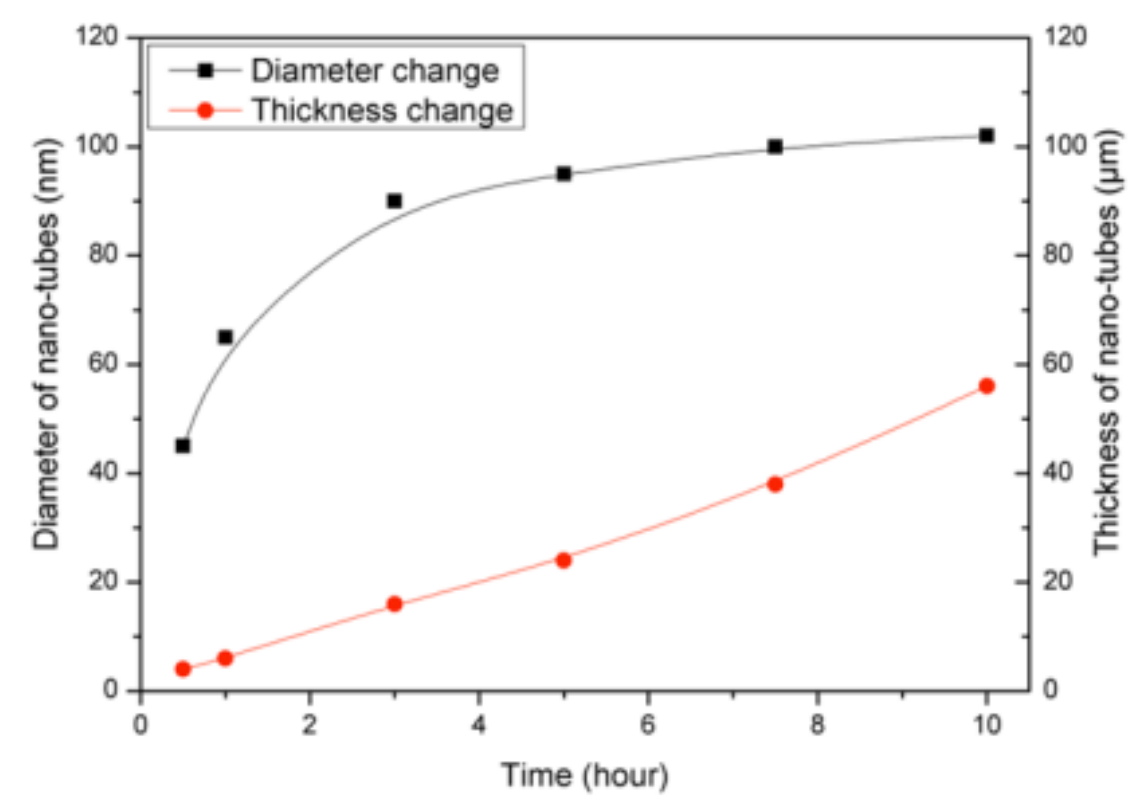

Figure 4 shows changes in the wall thickness depending on the depth of $\mathrm{TiO}_{2} \mathrm{NTs}$ layers. The surface of nano tubular layer was etched by plasma using Glow Discharge Optical Spectroscopy (GDOS) for varied durations in order to investigate change in the diameter through the $\mathrm{TiO}_{2} \mathrm{NTs}$. The inner diameter of the nanotube decreases from top to bottom of nano tubular structures, yielding a $\mathrm{V}$-shape of development of the diameter over the length. Cao et al. explain this situation with the deficiency in transportations of $\mathrm{F}^{-}$ions or F-compounds (such as $\left[\mathrm{TiF}_{6}\right]^{2-}$ ) in $\mathrm{TiO}_{2} \mathrm{NTs}_{\text {. The growth }}$ mechanism of the $\mathrm{TiO}_{2}$ NTs is governed by computing the process of anodization of $\mathrm{TiO}_{2}$ and selective etching of $\mathrm{TiO}_{2}$, which is driven by $\mathrm{F}^{-}$ion [8]. 
Figure 4. SEM micrographs displaying the diameter change along the layer thickness from top (a) to bottom (b) of the $\mathrm{TiO}_{2} \mathrm{NTs}$ synthesized by anodization of Ti in EG-based solutions.

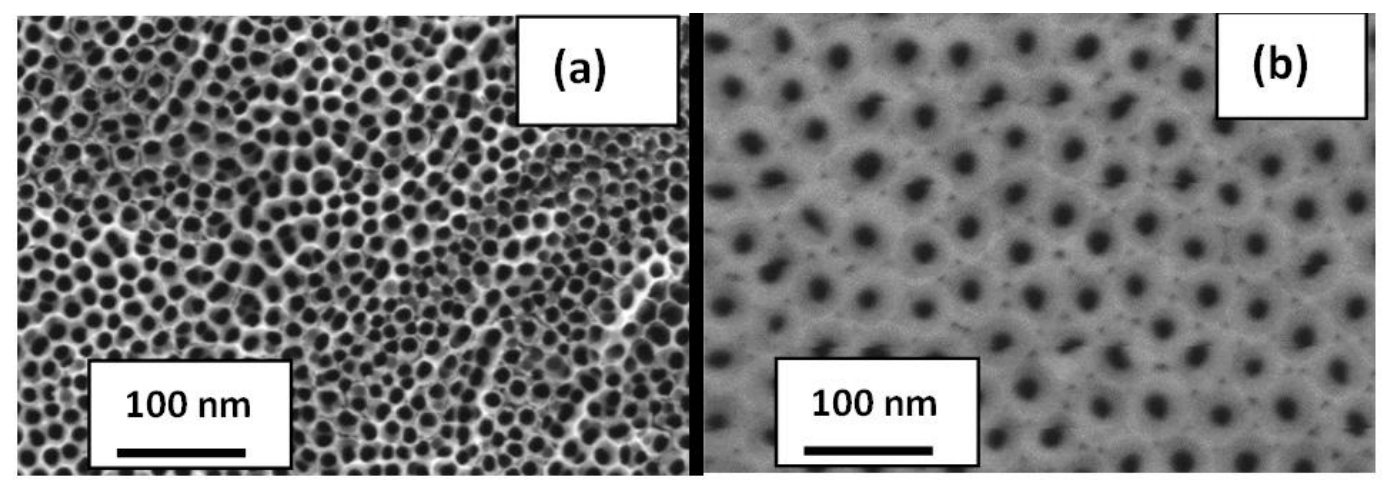

After doping and annealing processes, the $\mathrm{Cr}$ doped $\mathrm{TiO}_{2} \mathrm{NTs}$ were investigated by SEM which showed that the $\mathrm{TiO}_{2}$ NTs were visually intact. Figure 4a shows the SEM images of the Cr doped $\mathrm{TiO}_{2}$ NTs after $3 \mathrm{~h}$ annealing at $450{ }^{\circ} \mathrm{C}$. Under this annealing condition, no noticeable change in the morphology of $\mathrm{TiO}_{2}$ NTs was observed. The diameters of the $\mathrm{TiO}_{2}$ NTs showed no change after soaking in $\mathrm{Cr}^{3+}$-solution and the subsequent annealing process. In addition, a chromium content of app. $2 \%$ wt was detected by EDX analysis (see Figure $5 \mathrm{~b}$ ).

Figure 5. (a) Top-view SEM image of $\mathrm{TiO}_{2}$ NTs doped with $\mathrm{Cr}$ by the soaking method (b) Energy Dispersive X-ray (EDX) results obtained at this surface indicate the presence of chromium $(\mathrm{Cr})$.
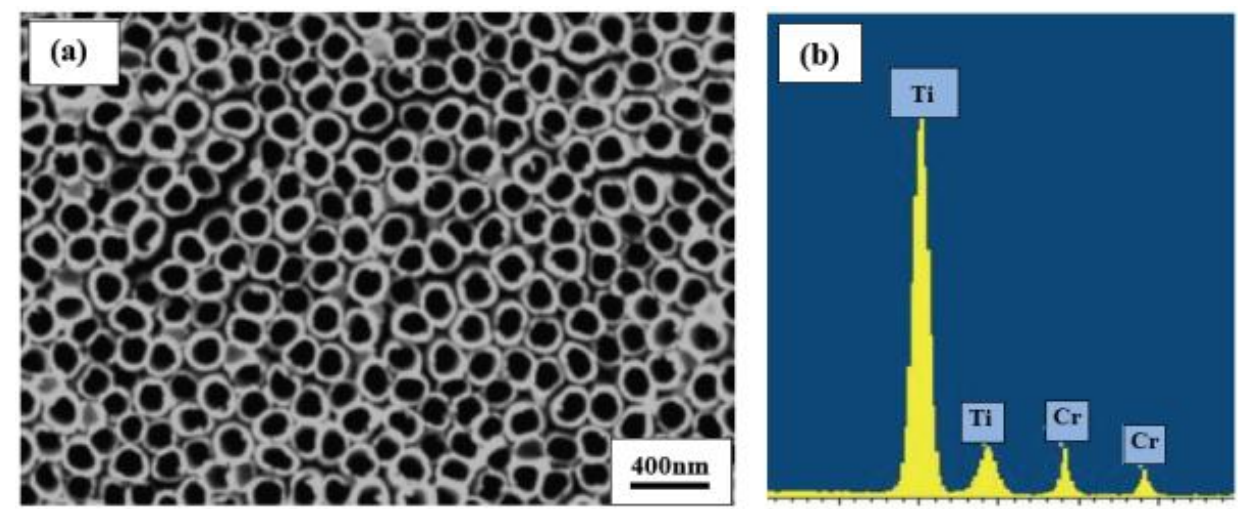

\subsection{Crystallization and Crystalline Phases of Undoped/Doped $\mathrm{TiO}_{2} \mathrm{NTS}$}

The undoped and $\mathrm{Cr}$ doped $\mathrm{TiO}_{2}$ NTs were investigated with XRD before and after annealing process. It is important to mention that, $\mathrm{Cr}$ doped $\mathrm{TiO}_{2} \mathrm{NTs}$ were amorphous as were the undoped $\mathrm{TiO}_{2}$ NTs before annealing process. Therefore, the XRD diffraction of as anodized $\mathrm{TiO}_{2} \mathrm{NTs}$, which were not shown here, yield only Ti-peaks coming from the substrate. XRD diffractions of both, un-doped $\mathrm{TiO}_{2}$ and $\mathrm{Cr}$ doped $\mathrm{TiO}_{2}$ NTs, display the presence of anatase phase after annealing at $450{ }^{\circ} \mathrm{C}$ in atmospheric air for $3 \mathrm{~h}$ (see Figure 6). In addition, the increase in the annealing temperature from $450{ }^{\circ} \mathrm{C}$ to $700{ }^{\circ} \mathrm{C}$ yielded a transformation of rutile phase form anatase phase. As Figure 6 shows, doping of $\mathrm{TiO}_{2}$ with chromium affects the anatase-to-rutile transformation by retarding the formation of rutile. The XRD diffractogrammes showed no $\mathrm{Cr}_{2} \mathrm{O}_{3}$ peaks, indicating that the chemical process 
used for doping leads to successful incorporation of $\mathrm{Cr}$ into the $\mathrm{TiO}_{2}$ lattice. Moreover, $\mathrm{XRD}$ diffractogrammes showed that both undoped and $\mathrm{Cr}$ doped $\mathrm{TiO}_{2} \mathrm{NTs}$ had anatase and rutile phase after

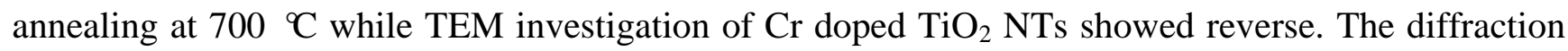
pattern of $\mathrm{Cr}$ doped $\mathrm{TiO}_{2}$ NTs showed that $\mathrm{Cr}$ doped $\mathrm{TiO}_{2} \mathrm{NTs}$ only had an anatase phase after annealing at $700{ }^{\circ} \mathrm{C}$ (see Figure 7). It is already reported in the literature that $\mathrm{Cr}$ doping of $\mathrm{TiO}_{2}$ retards the formation of anatase phase at lower temperatures and the anatase-to-rutile transformation at temperatures above $700{ }^{\circ} \mathrm{C}[9,10]$. Relying on this information, it is plausible that despite annealing at $700{ }^{\circ} \mathrm{C}, \mathrm{Cr}$ doped $\mathrm{TiO}_{2}$ NTs consist of only the anatase phase. However, the presence of rutile was not expected as detected by XRD. In order to clarify the reasons yielding the rutile peaks, detailed TEM investigation has been carried out which showed that $\mathrm{Cr}$ atoms exist only in the $\mathrm{TiO}_{2} \mathrm{NTs}$. In contrast, the bulk $\mathrm{TiO}_{2}$ layer between nanotubular $\mathrm{TiO}_{2}$ layer and titanium metal substrate (i.e., dense, thin $\mathrm{TiO}_{2}$ layer beneath the $\mathrm{TiO}_{2} \mathrm{NTs}$ ) does not contain any chromium atoms (see Figure 8d). As indicated, anatase-to-rutile transformation occurs at relatively lower temperatures for undoped $\mathrm{TiO}_{2} \mathrm{NTs}_{\mathrm{s}}$ and bulk $\mathrm{TiO}_{2}$ layers than that for $\mathrm{Cr}$ doped $\mathrm{TiO}_{2}$ NTs. Thus, it is assumed that the rutile peaks observed in the XRD pattern may be from the thin bulk $\mathrm{TiO}_{2}$ layer present beneath the $\mathrm{TiO}_{2} \mathrm{NTs}$.

Figure 6. XRD diffractogrammes of $\mathrm{TiO}_{2}$ and $\mathrm{Cr}$ doped $\mathrm{TiO}_{2}$ NTs after annealing at $700{ }^{\circ} \mathrm{C}$. (A: Anatase, R: Rutile and T: Titanium).

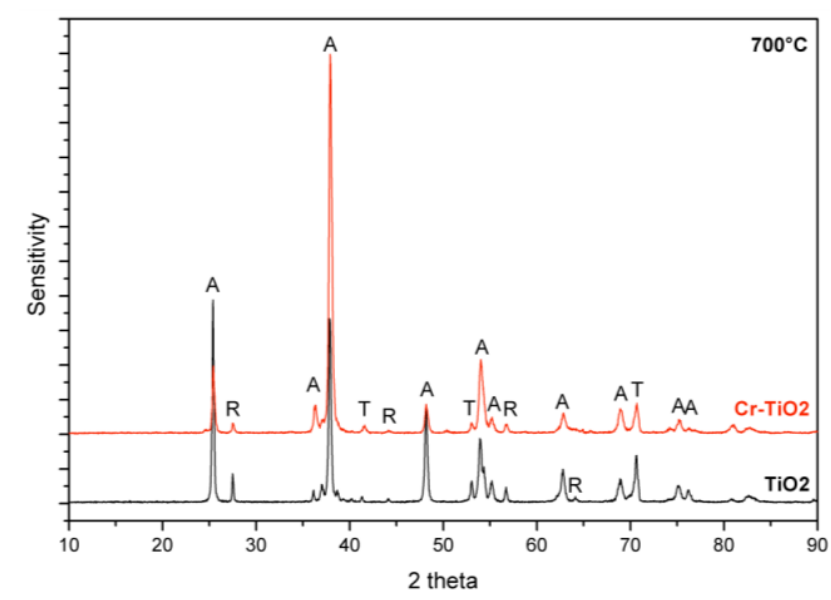

Figure 7. Corresponding diffraction pattern (a) and selected area electron diffraction (SAED) pattern (b) of $\mathrm{Cr}$ doped $\mathrm{TiO}_{2} \mathrm{NTs}$ away from substrate and thin bulk $\mathrm{TiO}_{2}$ layer.
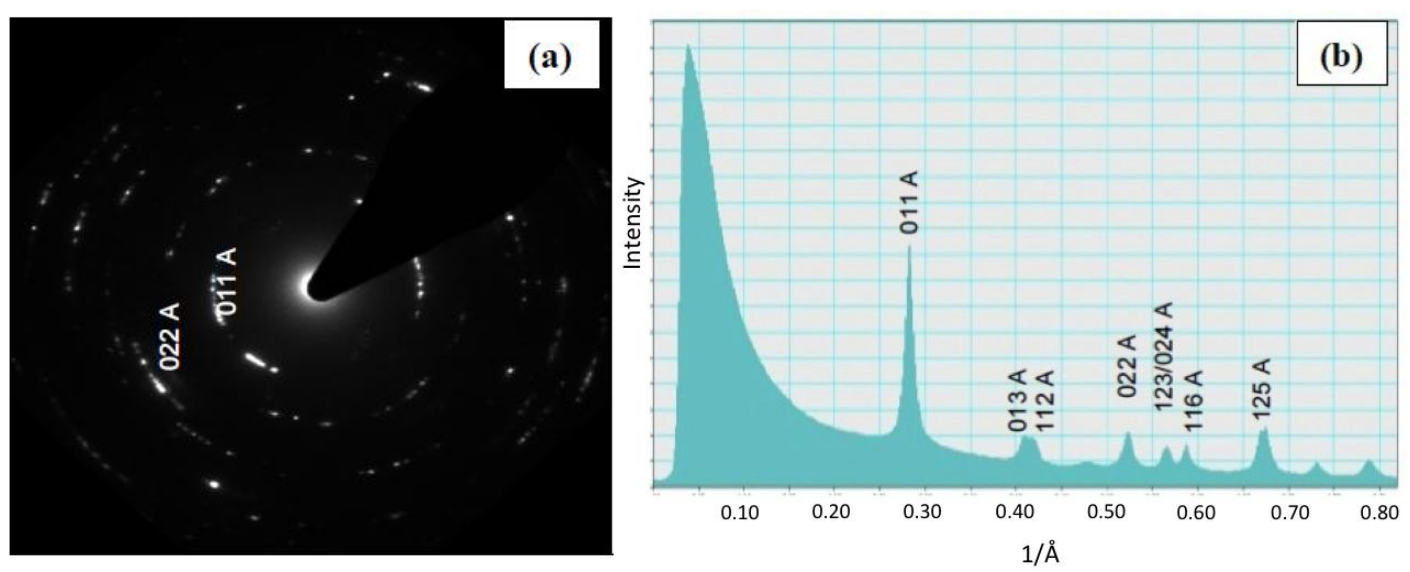
Figure 8. Analysis of the $\mathrm{Cr}$ doped $\mathrm{TiO}_{2}$ NTs by FE-TEM (a) high-angle annular dark-field (HAADF)-image and EDX-Mapping results of (b) titanium (c) oxygen and (d) chromium in the $\mathrm{Cr}$ doped $\mathrm{TiO}_{2}$ NTs. Chromium is detected only in $\mathrm{TiO}_{2} \mathrm{NTs}$, while no chromium is detected in the thin bulk $\mathrm{TiO}_{2}$ layer present at the bottom $\mathrm{TiO}_{2} \mathrm{NTs}$ (Figure 8d).
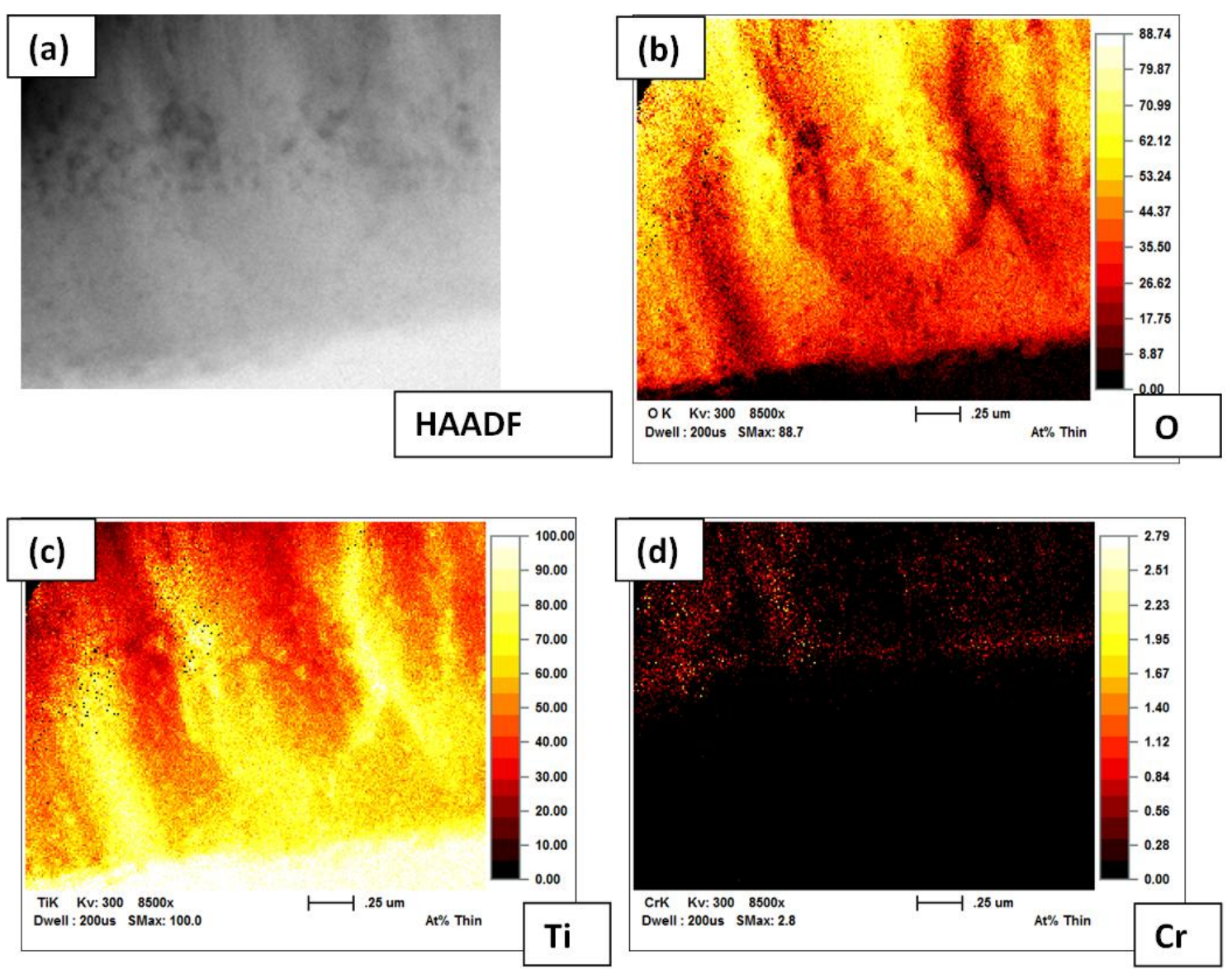

\subsection{Factors Influencing Sensor Response of Undoped and Cr Doped $\mathrm{TiO}_{2} \mathrm{NTs}$}

\subsubsection{Effect of Thickness on Gas Sensing Behavior}

In order to understand the sensing mechanism of $\mathrm{TiO}_{2} \mathrm{NTs}$, DC-response and AC-impedance measurements have been carried out for $\mathrm{TiO}_{2}$ NTs having different thickness. The variation of sensor response with two different thicknesses of $\mathrm{TiO}_{2}$ NT layers (6 to $12 \mu \mathrm{m}$ ) are given in Figure 9 a. $\mathrm{TiO}_{2}$ NTs having a thickness of 11-12 $\mu \mathrm{m}$ detect the gas concentration variation more selectively, while those of 5-6 $\mu \mathrm{m}$ thickness yield similar type of response toward all tested concentrations (i.e., 10 to $100 \mathrm{ppm}$ ). The sensor signals, $\mathrm{S}$ of the nanotubular layers with thicknesses varying from 6 to $24 \mu \mathrm{m}$ are given in Figure 9b. The increase in the thickness of $\mathrm{TiO}_{2} \mathrm{NTs}$ results in an improvement in the sensor response. The sensor signal, $S$ does not vary with the amount of test gas when thinner $\mathrm{TiO}_{2} \mathrm{NTs}$ (approx. $6 \mu \mathrm{m}$ ) are used. The thickness increase from 6 to $12 \mu \mathrm{m}$ exhibits a higher sensitivity toward $\mathrm{NO}_{2}$ depending on the amount of testing gas. On the other hand, no more sensitivity improvement can be detected when the thickness increases above $12 \mu \mathrm{m}$ (i.e., 18 or $24 \mu \mathrm{m}$ ). It appears that a critical thickness $\left(\mathrm{d}_{\text {crit. }}\right)$ exists at about a thickness between 6 and $12 \mu \mathrm{m}$. The impedance measurements support also these results. The impedance measurements of $\mathrm{TiO}_{2} \mathrm{NTs}$ having different thicknesses 
have been carried out towards $25 \mathrm{ppm} \mathrm{NO} 2$ in argon ambient gas atmosphere and in pure argon atmosphere (see Figure 10). The impedance spectra of $\mathrm{TiO}_{2} \mathrm{NTs}$ show solely the typical semi-circle part at high frequencies. As the thickness of $\mathrm{TiO}_{2} \mathrm{NTs}$ increases, an increase in the complex resistance, $\mathrm{Z}^{I}$ has been observed.

Figure 9. Responses of undoped $\mathrm{TiO}_{2}$ NTs for different thicknesses at $500{ }^{\circ} \mathrm{C}$ towards various $\mathrm{NO}_{2}$ concentrations (a) response versus time (b) response versus concentration.
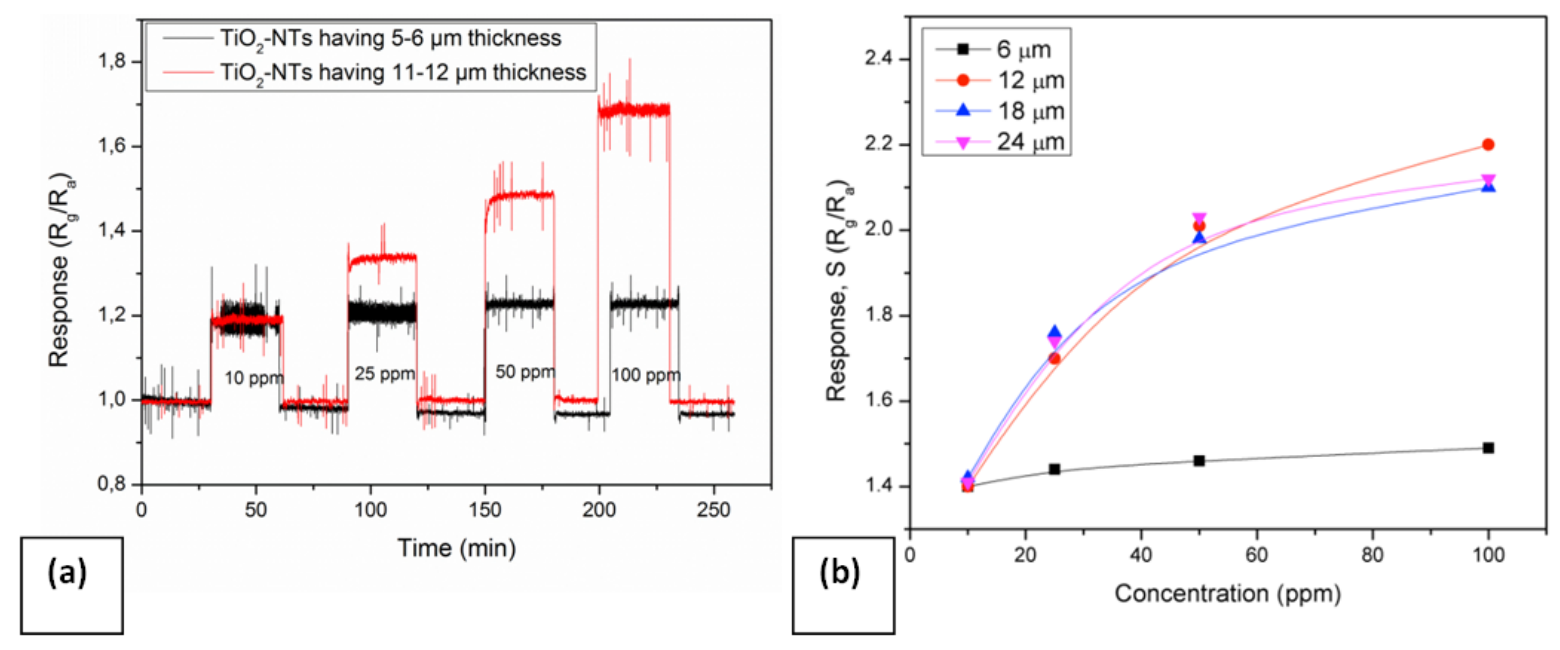

The equivalent circuit model employed in this study is given in Figure 11. According to this model, a serial connected $R_{1}\left\|C P E_{1}, R_{2}\right\| C P E_{2}$ and $C P E_{3}$ was created, which was then parallel connected with a $C_{0}$ representing the capacity of platinum electrodes. In the equivalent circuit model, the first compound, i.e., $R_{1} \| C P E_{1}$ belongs to the $\mathrm{TiO}_{2} \mathrm{NTs}, R_{1}$ representing the resistance of the $\mathrm{TiO}_{2} \mathrm{NTs}$. The constant phase element $(C P E)$ is represented with the depressed semicircle in the corresponding Nyquist impedance plot as given in the literature [11] and is a calculated parameter when the circuit element is behaving in between capacitor and resistor. The constant phase element $(C P E)$ is comprised by two components; $C P E-T$ and $C P E-P$. $C P E-T$ is a pseudo capacitance which is called $\mathrm{Q}$ and $C P E-P$ is related to the semi-circle in the Nyquist plot (depressed semicircle), normally used for the notation ' $n$ '. By using CPE-P and CPE-T and resistance, one can calculate the true capacitance for the electrodes. If $C P E-P$ equals approximately to 1 , then the $C P E$ turns theoretically to a capacitor, $C$ [12].

The second parallel contacted elements (i.e., $R_{2}$ and $C P E_{2}$ ) belong to the dense bulk $\mathrm{TiO}_{2}$ layer present between the $\mathrm{TiO}_{2} \mathrm{NTs}$ and Ti metal. Hereby, $R_{2}$ represents the resistance of bulk $\mathrm{TiO}_{2}$ layer.

Lastly, $C P E_{3}$ defines gas depended interface in order to figure out the effect of diffusion and can be regarded as the Warburg Element [12]. $C P E_{3}-T$ value is related to the amount of the carrier electrons on the system with a different mechanism such as diffusion [13-15]. Lack of diffusion in the system can cause a decrease in the $C P E_{3}-T$ values. It can be seen in Table 1 that $C P E_{3}-T$ is getting smaller with the increase of nano-tubular layer thickness and even constant above a certain thickness, indicating the reduction of diffusion above this NT thickness.

Thus, these results can be used to define the relation between sensor signal and layer thickness. On the contrary to general opinion, the present results reveal that sensor signal of $\mathrm{TiO}_{2} \mathrm{NT}$ layers does not deteriorate on increase of layer thickness above a critical length $\left(\mathrm{d}_{\text {crit }}\right)$ despite the fact that slower gas diffusion is anticipated as the thickness of diffusion path increases. An increase in the thickness of 
$\mathrm{TiO}_{2}$ NTs from 12 to $24 \mu \mathrm{m}$ resulted in a reduction of gas diffusion in the $\mathrm{TiO}_{2} \mathrm{NTs}$, but not in the sensitivity. At very low thickness state (e.g., $6 \mu \mathrm{m}$ ), the resistance values of the $\mathrm{TiO}_{2} \mathrm{NTs}$ and the bulk $\mathrm{TiO}_{2}$ layer are close to each other. The electrons might have been transferred from one electrode to another electrode through both $\mathrm{TiO}_{2} \mathrm{NTs}$ and the bulk $\mathrm{TiO}_{2}$ layer. However, after an increase in the nanotube thickness to a critical point $\left(\mathrm{d}_{\text {crit }}\right)$, the electron flow to and within the bulk $\mathrm{TiO}_{2}$ layers starts to be inhibited. Since less gas diffuses through the bottom layer of the nanotubes, less electron flow occurs in the bulk $\mathrm{TiO}_{2}$ layer. Therefore, it can be stated that the $\mathrm{TiO}_{2} \mathrm{NTs}$ show higher resistance changes (which means higher sensitivity) as the layer thickness increases up to a critical thickness $\left(\mathrm{d}_{\text {crit }}\right)$.

Figure 10. Nyquist plots of the $\mathrm{TiO}_{2}$ NTs at different layer thickness (a) by exposing only to argon (b) towards $25 \mathrm{ppm} \mathrm{NO}$ in argon carrier gas at $300{ }^{\circ} \mathrm{C}$.
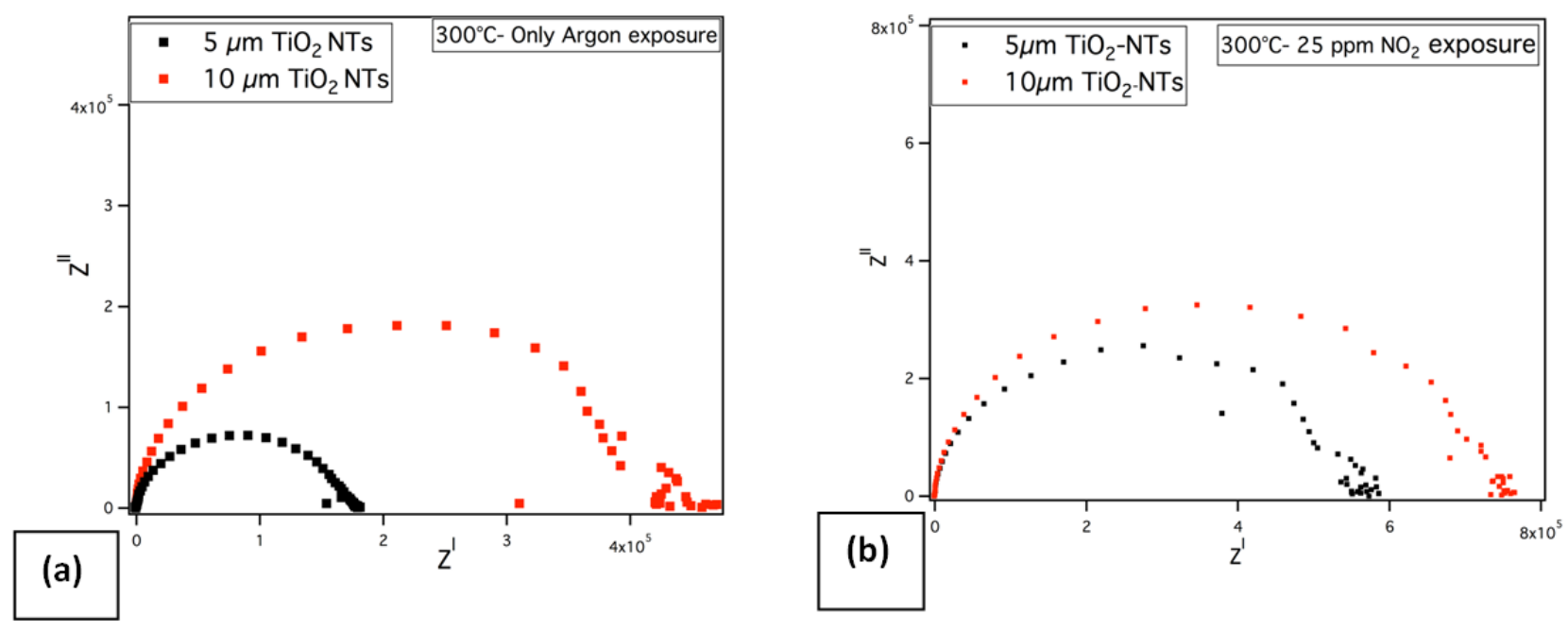

Figure 11. Equivalent circuit model of the sensor with $\mathrm{TiO}_{2}$ NTs indicating the corresponding sensor parts $\mathrm{C}_{0}$ : capacitive, $\mathrm{R}_{1}$ and $\mathrm{R}_{2}$ : resistive.

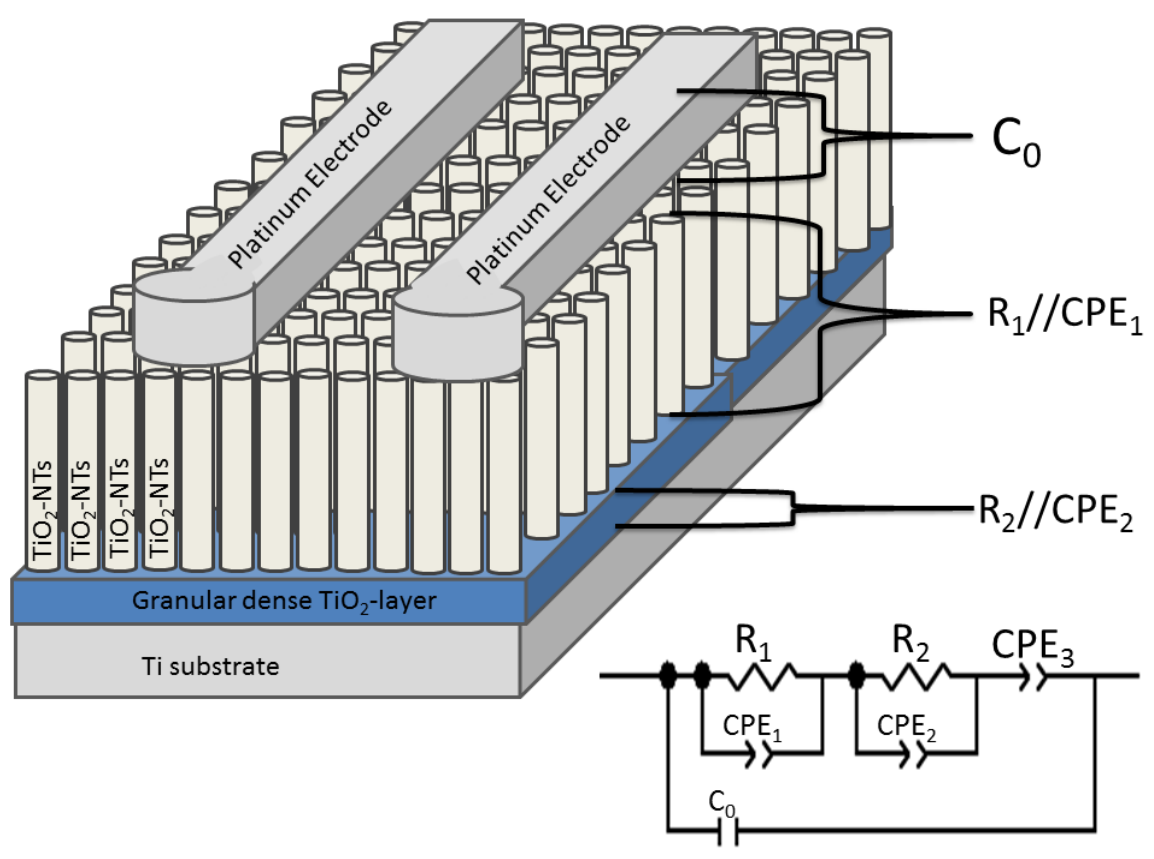


Table 1. Change in resistance $\left(\mathrm{R}_{1}, \mathrm{R}_{2}\right)$ and CPE-values of undoped $\mathrm{TiO}_{2} \mathrm{NT}$ s layer and the bulk $\mathrm{TiO}_{2}$ depending on NTs thickness towards different amounts of $\mathrm{NO}_{2}$ at each selected measurement. Colored columns indicate the constant values, and thus reduced diffusion.

\begin{tabular}{|c|c|c|c|c|c|c|c|c|}
\hline \multirow[b]{2}{*}{ Thickness-Gas } & \multirow[b]{2}{*}{$\begin{array}{c}\mathbf{R}_{\mathbf{1}} \\
{[\Omega]}\end{array}$} & \multicolumn{2}{|c|}{$\mathrm{CPE}_{1}$} & \multirow[b]{2}{*}{$\begin{array}{c}\mathbf{R}_{\mathbf{2}} \\
{[\mathbf{\Omega}]}\end{array}$} & \multicolumn{2}{|c|}{$\mathrm{CPE}_{2}$} & \multicolumn{2}{|c|}{$\mathrm{CPE}_{3}$} \\
\hline & & $\begin{array}{c}\mathbf{T} \\
{[\mathbf{s P} / \mathbf{\Omega}]}\end{array}$ & $\mathbf{P}$ & & $\begin{array}{c}\mathrm{T} \\
{[\mathrm{sP} / \Omega]}\end{array}$ & $\mathbf{P}$ & $\begin{array}{c}\mathbf{T} \\
{[\mathrm{s}]}\end{array}$ & $\mathbf{P}$ \\
\hline $6 \mu \mathrm{m}-$ Argon & $3.5 \mathrm{E} 5$ & $1 \mathrm{E}-7$ & 0.9 & $1.4 \mathrm{E} 5$ & $3.8 \mathrm{E}-6$ & 0.24 & 0.001 & 0.1 \\
\hline $12 \mu \mathrm{m}$-Argon & $5.2 \mathrm{E} 5$ & $1 \mathrm{E}-7$ & 0.7 & $2.3 \mathrm{E} 3$ & $9 \mathrm{E}-6$ & 0.5 & $1.2 \mathrm{E}-4$ & 0.2 \\
\hline $18 \mu \mathrm{m}-A$ rgon & $5.5 \mathrm{E} 5$ & $1 \mathrm{E}-7$ & 0.9 & $2.4 \mathrm{E} 3$ & $3.8 \mathrm{E}-6$ & 0.24 & $1.3 \mathrm{E}-4$ & 0.1 \\
\hline $24 \mu \mathrm{m}$-Argon & $5.6 \mathrm{E} 5$ & $1 \mathrm{E}-7$ & 0.7 & $2.3 \mathrm{E} 3$ & $9 \mathrm{E}-6$ & 0.5 & $1.3 \mathrm{E}-4$ & 0.2 \\
\hline $6 \mu \mathrm{m}-25 \mathrm{ppm} \mathrm{NO} \mathrm{N}_{2}$ in Argon & $4.2 \mathrm{E} 5$ & $1.2 \mathrm{E}-8$ & 0.9 & $3.3 \mathrm{E} 5$ & $6.6 \mathrm{E}-6$ & 0.27 & 0.004 & 0.1 \\
\hline $12 \mu \mathrm{m}-25 \mathrm{ppm} \mathrm{NO}_{2}$ in Argon & $7.2 \mathrm{E} 5$ & $1 \mathrm{E}-7$ & 0.8 & $4.5 \mathrm{E} 3$ & 4.9E-7 & 0.6 & $2.1 \mathrm{E}-4$ & 0.2 \\
\hline $18 \mu \mathrm{m}-25 \mathrm{ppm} \mathrm{NO}_{2}$ in Argon & 7.4E5 & $1.2 \mathrm{E}-8$ & 0.9 & $3.5 \mathrm{E} 3$ & $6.6 \mathrm{E}-6$ & 0.27 & $2.6 \mathrm{E}-4$ & 0.1 \\
\hline $24 \mu \mathrm{m}-25 \mathrm{ppm} \mathrm{NO} \mathrm{NO}_{2}$ in Argon & 7.2E5 & $1 \mathrm{E}-7$ & 0.8 & $2.5 \mathrm{E} 3$ & 4.9E-7 & 0.6 & $2.6 \mathrm{E}-4$ & 0.2 \\
\hline
\end{tabular}

\subsubsection{Effect of Doping on Gas Sensing Mechanism}

The sensor response curves obtained with a $12 \mu \mathrm{m}$ thick $\mathrm{TiO}_{2}$ NT layer in Figure 12 exhibit that the undoped $\mathrm{TiO}_{2}$ NT yields n-type sensor response, while the $\mathrm{Cr}$ doped $\mathrm{TiO}_{2} \mathrm{NT}$ behaves as p-type semi-conductor under $\mathrm{NO}_{2}$-exposure. Considering the XRD investigation, this alteration in the sensor response type (i.e., in the semiconductor type) can be firstly attributed to the presence of rutile-phase. However, according to Savage et al., p-type semiconductor behavior can only be observed by the presence of almost pure rutile phase. After their observations, n-type semiconductor behavior is likely to be observed with a sensor layer (e.g., anatase and rutile phase mixture), which contains less than $75 \%$ rutile, being exposed to an oxidizing gas [16]. Moreover, our TEM investigations showed that $\mathrm{Cr}$ doped $\mathrm{TiO}_{2}$ NTs which were annealed at $700{ }^{\circ} \mathrm{C}$ contain solely anatase phase. Thus, the improved sensor response of the $\mathrm{Cr}$ doped $\mathrm{TiO}_{2}$ NTs with p-type behavior can be attributed to the $\mathrm{Cr}^{3+}$ doping which probably induces oxygen vacancies and thus facilitates the transport of charge carriers.

Figure 12. Responses of the undoped and $\mathrm{Cr}$ doped $\mathrm{TiO}_{2}-\mathrm{NT}$ s sensors having a thickness of $12 \mu \mathrm{m}$ and annealed at $700{ }^{\circ} \mathrm{C}$ towards various $\mathrm{NO}_{2}$ concentrations in argon carrier gas at $500{ }^{\circ} \mathrm{C}$.

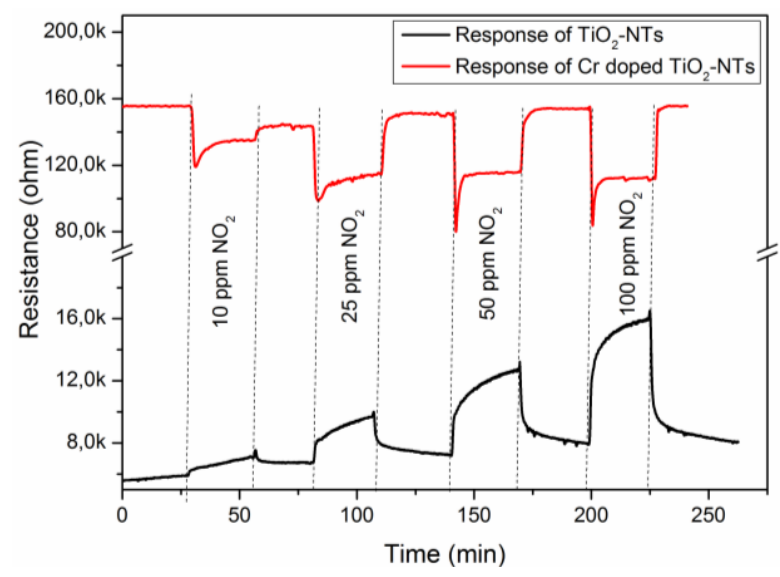

Relying on their close ionic radius $\left(\mathrm{Ti}^{4+}\right.$ in hexa-coordination is $0.745 \AA$; while $0.755 \AA$ for $\mathrm{Cr}^{3+}$ ), it can be postulated that the incorporation of trivalent $\mathrm{Cr}^{3+}$ into the $\mathrm{TiO}_{2}$-lattice will occur without any 
distortion of the lattice, simply via displacement of $\mathrm{Ti}^{4+}$-sites. Upon substitution of $\mathrm{Ti}^{4+}$ by the $\mathrm{Cr}^{3+}$; the original oxygen atom of one $\mathrm{Ti}-\mathrm{O}$ bond becomes electronegative resulting in a shift from its original site. Cr-substitution in Ti-sites and $\mathrm{O}_{\mathrm{o}}$ denotes an oxygen atom at its normal lattice site, resulting in oxygen vacancies, $V_{\mathrm{O}}$. As a result of $\mathrm{Cr}$ doping, oxygen vacancies with a positive charge will be formed.

The Nyquist plot of the $\mathrm{Cr}$ doped $\mathrm{TiO}_{2}$ NTs for different concentrations of $\mathrm{NO}_{2}(25-50$ and $100 \mathrm{ppm}$ ) at $300{ }^{\circ} \mathrm{C}$ and their fitting results are given in Figure 13. The impedance spectrum of the $\mathrm{Cr}$ doped $\mathrm{TiO}_{2}$ NTs differs from that of undoped $\mathrm{TiO}_{2} \mathrm{NTs}$, displaying two semi-circle parts. The first semi-circle is related to the grain boundary conductivity and the second one is to the bulk conductivity. Furthermore, there is one linear part that is related with the response of electrode [17]. The linear part of the impedance spectra shrinks with the $\mathrm{NO}_{2}$-concentrations rising to 25,50 and $100 \mathrm{ppm}$ respectively in argon atmosphere (see Figure 13a). The same equivalent circuit model which is given in Figure 11 is used here too in order to obtain the fitting curve. The equivalent circuit model and measurements, which were carried out at $300{ }^{\circ} \mathrm{C}$ in argon, yield a perfect fit, as can be seen in Figure 13b. The effect of temperature on sensing mechanism was also figured out and it was given in Figure 13c,d. At higher temperatures, the impedance spectra display no longer two semi-circles; instead, contains one semi-circle which is related to the grain boundary conductivity at higher frequency and one linear part at low frequencies corresponding to the diffusion of sensing gas.

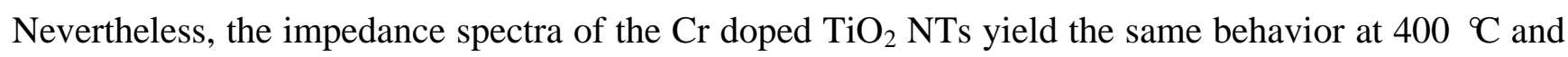
at $300{ }^{\circ} \mathrm{C}$. At higher concentrations of $\mathrm{NO}_{2}$, the linear part of the spectra shrinks.

Figure 13. Impedance spectra of $\mathrm{Cr}$ doped $\mathrm{TiO}_{2}$ NTs under different concentrations of $\mathrm{NO}_{2}$ at $300{ }^{\circ} \mathrm{C}$ (a) measurement results (b) fitting result combined with measurement and at $400{ }^{\circ} \mathrm{C}$ (c) measurements (d) fitting result combined with measurement.
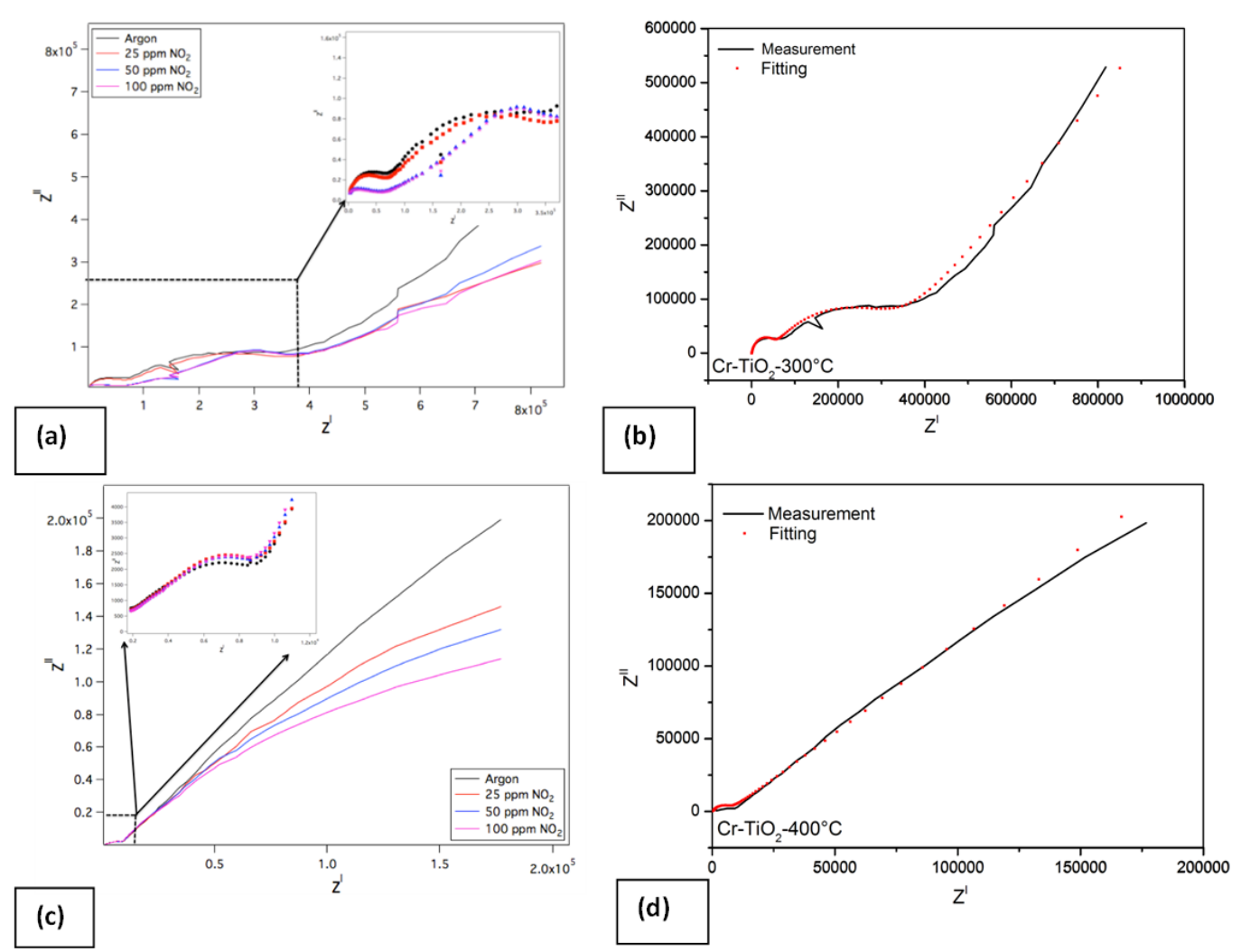
The numerical values of the equivalent circuit's elements for $\mathrm{Cr}$ doped $\mathrm{TiO}_{2} \mathrm{NTs}$ are given in Table 2. It is known that if CPE-P values of constant phase elements equals to approximately 1 , then the CPE turns theoretically to a capacitor [13]. As it can be seen from Table 2, CPE1-P values are 1, which means CPE elements for $\mathrm{Cr}$ doped $\mathrm{TiO}_{2} \mathrm{NTs}$ layers behave like capacitor at all temperature ranges. The use of this information can make an important inference for the determination of which $R \| C P E$ group represents which $\mathrm{TiO}_{2}$ layer. Above, it is described that the same element group (i.e., parallel connected $R \| C P E$ ) is used to define and differentiate between two different layers, i.e., $\mathrm{TiO}_{2}$ NTs layer and dense bulk $\mathrm{TiO}_{2}$ layer lying between nanotubular layer and titanium.

Table 2. Fitting parameters of the $\mathrm{Cr}$ doped $\mathrm{TiO}_{2} \mathrm{NTs}$.

\begin{tabular}{|c|c|c|c|c|c|c|c|c|}
\hline \multirow[b]{2}{*}{ Temperature-Gas content } & \multirow[b]{2}{*}{$\begin{array}{c}\mathbf{R}_{1} \\
{[\Omega]}\end{array}$} & \multicolumn{2}{|c|}{$\mathrm{CPE}_{1}$} & \multirow[b]{2}{*}{$\begin{array}{c}\mathbf{R}_{2} \\
{[\Omega]}\end{array}$} & \multicolumn{2}{|c|}{$\mathrm{CPE}_{2}$} & \multicolumn{2}{|c|}{$\mathrm{CPE}_{3}$} \\
\hline & & $\begin{array}{c}\mathbf{T} \\
{[\mathbf{s P} / \mathbf{\Omega}]}\end{array}$ & $\mathbf{P}$ & & $\begin{array}{c}\mathbf{T} \\
{[\mathrm{sP} / \Omega]}\end{array}$ & $\mathbf{P}$ & $\begin{array}{c}\mathbf{T} \\
{[\mathbf{s}]}\end{array}$ & $\mathbf{P}$ \\
\hline $300{ }^{\circ} \mathrm{C}$-pure Argon & 43,000 & 5.9E-9 & 1 & 285,000 & $9 \mathrm{E}-7$ & 0,58 & $1.7 \mathrm{E}-5$ & 0.5 \\
\hline $300{ }^{\circ} \mathrm{C}-25 \mathrm{ppm} \mathrm{NO}_{2}$ in Argon & 40,000 & $1.6 \mathrm{E}-8$ & 1 & 336,000 & $1.9 \mathrm{E}-6$ & 0.56 & $2.5 \mathrm{E}-5$ & 0.65 \\
\hline $300{ }^{\circ} \mathrm{C}-50 \mathrm{ppm} \mathrm{NO}_{2}$ in Argon & 23,000 & $4 \mathrm{E}-9$ & 1 & 600,000 & $2 \mathrm{E}-6$ & 0.55 & $3.5 \mathrm{E} 5$ & 0.65 \\
\hline $300{ }^{\circ} \mathrm{C}-100 \mathrm{ppm} \mathrm{NO}_{2}$ in Argon & 22,000 & $8 \mathrm{E}-9$ & 1 & 620,000 & $2 \mathrm{E}-6$ & 0.7 & $3.8 \mathrm{E}-5$ & 0.85 \\
\hline $400{ }^{\circ} \mathrm{C}$-pure Argon & 5,000 & $3 \mathrm{E}-6$ & 1 & 6,000 & 0.002 & 0.3 & 7.4E-5 & 0.58 \\
\hline $400{ }^{\circ} \mathrm{C}-25 \mathrm{ppm} \mathrm{NO}_{2}$ in Argon & 4,100 & $3 \mathrm{E}-6$ & 1 & 6,000 & 0.002 & 0.3 & $6 \mathrm{E}-5$ & 0.59 \\
\hline $400{ }^{\circ} \mathrm{C}-50 \mathrm{ppm} \mathrm{NO}_{2}$ in Argon & 3,300 & $3 \mathrm{E}-6$ & 1 & 6,000 & 0.002 & 0.3 & $5.9 \mathrm{E}-5$ & 0.69 \\
\hline $400{ }^{\circ} \mathrm{C}-100 \mathrm{ppm} \mathrm{NO}_{2}$ in Argon & 2,900 & $3 \mathrm{E}-6$ & 1 & 6,000 & 0.002 & 0.3 & $5.7 \mathrm{E}-5$ & 0.71 \\
\hline $500{ }^{\circ} \mathrm{C}$-pure Argon & 800 & $5 \mathrm{E}-7$ & 1 & 450 & 0.0002 & 0.5 & $1.9 \mathrm{E}-4$ & 0.5 \\
\hline $500{ }^{\circ} \mathrm{C}-25 \mathrm{ppm} \mathrm{NO}_{2}$ in & 700 & $5 \mathrm{E}-7$ & 1 & 450 & 0.0002 & 0.5 & $1.7 \mathrm{E}-4$ & 0.51 \\
\hline $500{ }^{\circ} \mathrm{C}-50 \mathrm{ppm} \mathrm{NO} \mathrm{NO}_{2}$ in Argon & 450 & $5 \mathrm{E}-7$ & 1 & 450 & 0.0002 & 0.5 & $1.6 \mathrm{E}-4$ & 0.51 \\
\hline $500{ }^{\circ} \mathrm{C}-100 \mathrm{ppm} \mathrm{NO} \mathrm{N}_{2}$ in Argon & 400 & $5 \mathrm{E}-7$ & 1 & 450 & 0.0002 & 0.5 & $1.6 \mathrm{E}-4$ & 0.54 \\
\hline
\end{tabular}

The resistance values of the first compound $R_{l}$, which represents the $\mathrm{TiO}_{2} \mathrm{NTs}$, decreases as the amount of the test gas $\mathrm{NO}_{2}$ concentration increases. On the other hand, the resistance values of the second compound $R_{2}$, which represents bulk $\mathrm{TiO}_{2}$ layer, increases with increasing $\mathrm{NO}_{2}$ amount. As explained previously, a decrease in resistance towards oxidizing gases is a typical behavior for p-type semi-conductive metal-oxides; while an increase in the resistance for $n$ - type semi-conductive metal-oxide is expected. TEM investigations and EDX-mapping results showed that $\mathrm{Cr}$ is situated only inside the $\mathrm{TiO}_{2}$ NTs, while no presence of Cr was detected by TEM in the bulk $\mathrm{TiO}_{2}$ layer which lies beneath the nanotubular $\mathrm{TiO}_{2}$ (see Figure 6). As a result, while $\mathrm{Cr}$ doped $\mathrm{TiO}_{2} \mathrm{NTs}$ exhibits p-type sensor behavior, the bulk $\mathrm{TiO}_{2}$ layer contributes to the behavior of n-type semiconductor. After all, the different responses at $R_{1}$ and $R_{2}$ values towards $\mathrm{NO}_{2}$ support this idea correlating the relation between the different circuit elements with the different morphological parts of $\mathrm{TiO}_{2}$.

Impedance spectra show a reduction at the linear part of the graph (i.e., low frequency part) with the increase of test-gas concentrations. At equivalent circuit model, the linear part of the spectra is found to depend on the value of $C P E_{3}$, which is responsible for the gas related interface. It is known that the $C P E-T$ value varies mostly with the amount of the transported electrons at the system. Increasing the amount of $\mathrm{NO}_{2}$ in the system causes more reactions on the walls of the $\mathrm{TiO}_{2} \mathrm{NTs}$. This means that the more reactions occur on the wall surface, the more electrons are transported within the system. Thus, 
the observed increase in the value of $C P E_{3}-T$ is plausible and this causes a lowering at the linear part of the impedance spectra as the amount of the test gas increases.

Temperature dependent change in resistance for semiconductors is given with the Equation (1):

$$
\frac{1}{R(T)}=\frac{1}{R_{0}} * \exp (-E / k T)
$$

The applied sensor behaves as a chemo-resistive system therefore the Equation (2) which applies generally for resistors is used for TCR (Temperature Coefficient of Resistance) calculations [18].

$$
R(T)=R_{0}\left[1+\alpha\left(T-T_{0}\right)\right]
$$

where $R_{0}$ is the resistance at the temperature $T_{0}$ and $\alpha$ is the temperature coefficient of resistance (TCR) which is usually positive for metals at room temperature and negative for semiconductors and insulators. By applying this equation, easier experimental measurement is possible to demonstrate that the employed NTs exhibit negative TCR values. As Figure 14 shows, both $\mathrm{TiO}_{2}$ NTs samples (undoped and $\mathrm{Cr}$ doped) have negative TCR-values, which means that the temperature increase causes a decrease in the surface resistance of semi-conductive nanotubular layer.

Figure 14. Temperature coefficient of resistance (TCR) values of the undoped and $\mathrm{Cr}$ doped $\mathrm{TiO}_{2}$ NTs depending on different temperatures.

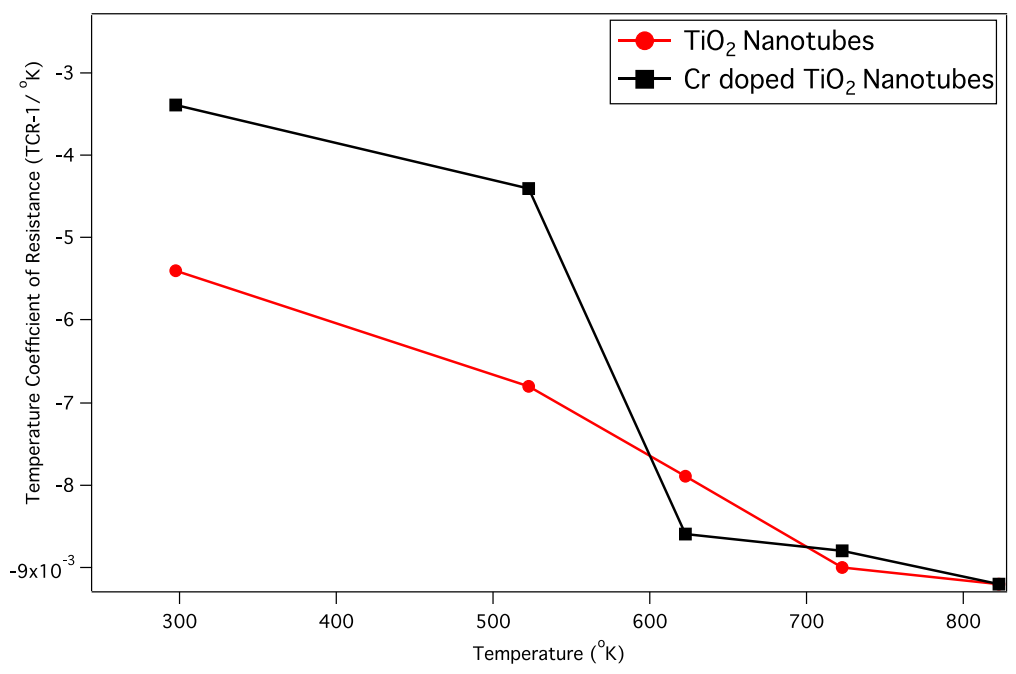

The used equivalent circuit parameters showed that the increase of the temperature causes a decrease in both resistance values, $R_{1}$ and $R_{2}$, as expected. The resistance of the $\mathrm{Cr}$ doped $\mathrm{TiO}_{2} \mathrm{NTs}$ which is represented by $R_{1}$ decreases also depending on $\mathrm{NO}_{2}$ concentration at higher concentrations. On the other hand, the resistance of the bulk $\mathrm{TiO}_{2}$ layer towards test gas, $\mathrm{NO}_{2}$ changes only at lower temperature (below $400{ }^{\circ} \mathrm{C}$ ). Above $400{ }^{\circ} \mathrm{C}$, the bulk $\mathrm{TiO}_{2}$ layer shows no response to the $\mathrm{NO}_{2}$ concentration changes. At the temperatures above $400{ }^{\circ} \mathrm{C}$, the bulk conductivity of bulk $\mathrm{TiO}_{2}$ becomes less effective as the grain boundary of the nano-tubes becomes more dominant. In addition, $\mathrm{CPE}_{2}-\mathrm{T}$ value of the bulk $\mathrm{TiO}_{2}$ layer remains stable even at higher $\mathrm{NO}_{2}$ concentrations. The constant $\mathrm{CPE}_{2}-\mathrm{T}$ rate is a sign of constant electron transfer in the bulk $\mathrm{TiO}_{2}$ layer. It is already reported in the literature that the grain boundary conductivity increases with the increase of temperature [19-21]. As indicated in the literature as well as the obtained impedance results show, the grain boundary conductivity of the 
$\mathrm{Cr}$ doped $\mathrm{TiO}_{2}$ NTs became more dominant than the conductivity of thin bulk $\mathrm{TiO}_{2}$ layer as temperature increases from $300{ }^{\circ} \mathrm{C}$ to $400{ }^{\circ} \mathrm{C}$. In other words, increased grain boundary conductivity achieved by $\mathrm{Cr}$ doping provides an easy pathway for electron transfer eliminating the role of denser thin bulk $\mathrm{TiO}_{2}$-layer beneath the $\mathrm{TiO}_{2}$ NTs. Thus, it can be attributed that the doped transient oxides (e.g., $\mathrm{TiO}_{2}$-NTs) may lead to higher sensitivity in gas sensors. However, no further influence of grain boundary or bulk conductivity can be anticipated for the sensors selectivity [22]. It is more likely that selectivity of a sensor layer will relate to the band gap structure of the sensing material.

\section{Conclusions}

In this work the focus has been given onto the understanding the mechanism of the $\mathrm{TiO}_{2} \mathrm{NTs}_{\text {and }}$ doping effect on sensing behavior using the equivalent circuit model of impedance response towards $\mathrm{NO}_{2}$.Vertically aligned $\mathrm{TiO}_{2} \mathrm{NTs}$ were synthetized through the anodization process in an EG-based solution. $\mathrm{Cr}$ doping into $\mathrm{TiO}_{2} \mathrm{NTs}$ process was achieved by employing a simple but effective chemical route. Both un-doped and $\mathrm{Cr}$ doped $\mathrm{TiO}_{2} \mathrm{NTs}$ yield a stable response towards $\mathrm{NO}_{2}$ at test temperatures as high as $500{ }^{\circ} \mathrm{C}$. The impedance measurements show that the sensing mechanism develops in dependency of $\mathrm{TiO}_{2}$ NTs thickness, temperature or dopant elements. The thickness of the nano-tubular layer has an influence on sensing mechanism until a certain thickness $\left(\mathrm{d}_{\text {crit. }}\right)$ is reached. However, after this critical point, the thickness does not affect the sensing properties. This situation can probably be related to the lack of diffusion. The grain boundary and bulk conductivity appear to be the main control mechanisms of sensing in these layers. The grain boundary conductivity is mostly related to the conductivity of the nano-tubular part of the sensor, and the bulk conductivity is related with the dense oxide layer, which is present beneath the nano-tubular oxide layer. It is observed that the grain boundary conductivity could be increased either by increasing the temperature or doping into the $\mathrm{TiO}_{2} \mathrm{NTs}_{\text {. }}$

\section{Conflicts of Interest}

The authors declare no conflict of interest.

\section{References}

1. Yamazoe, N. New approaches for improving semiconductor gas sensors. Sens. Actuators B 1991, 5, 7-19.

2. Kim, I.-D.; Rothschild, A.; Tuller, H. Advances and new directions in gas-sensing devices. Acta Met. 2013, 61, 974-1000.

3. Şennik, E.; Çolak, Z.; Kılınç, N.; Öztürk, Z.Z. Synthesis of highly-ordered $\mathrm{TiO}_{2}$ nanotubes for a hydrogen sensor. Int. J. Hyd. Energy 2010, 35, 4420-4427.

4. Comini, E.; Sberveglier, G. Metal oxide nanowires as chemical sensors. Mater. Today 2010, 13, 36-44.

5. Gönüllü, Y.; Mondragón, G.M.R.; Saruhan, B.; Ürgen, M. Improvement of gas sensing performance of $\mathrm{TiO}_{2}$ towards $\mathrm{NO}_{2}$ by nano-tubular structuring. Sens. Actuators B 2012, 169, 151-160.

6. Jun, T.H.; Lee, K.S. Cr-doped $\mathrm{TiO}_{2}$ thin films deposited by RF-sputtering. Mater. Lett. 2010, 64, 2287-2289. 
7. Choia, Y.; Seeleya, Z.; Bandyopadhyaya, A.; Bosea, S.; Akbar, S.A. Aluminum-doped $\mathrm{TiO}_{2}$ nano-powders for gas sensors. Sens. Actuoators B 2007, 124, 111-117.

8. Coa, C.; Li, J.; Wang, X.; Song, X.; Sun, Z. Current characterisation and growth mechanism of anodic titania nanotube arrays. J. Mater. Res. 2011, 26, 437-442.

9. Liu, S.-Y.; Tang, Q.-L.; Feng, Q.-G. Synthesis of S/Cr doped mesoporous $\mathrm{TiO}_{2}$ with high-active visible light degradation property via solid state reaction route. Appl. Surf. Sci. 2011, 257, 5544-5551.

10. Ghicov, A.; Schmidt, B.; Kunze, J.; Schmuki, P. Photoresponse in the visible range from $\mathrm{Cr}$ doped $\mathrm{TiO}_{2}$ nanotubes. Chem. Phys. Lett. 2007, 433, 323-326.

11. Wang, M.; Wang, L.; Wang, G.; Ji, X.; Bai, Y.; Li, T.; Gong, S.; Li, J. Application of impedance spectroscopy for monitoring colloid Au-enhanced antibody immobilization and antibody-antigen reactions. Biosens. Bioelectron. 2004, 19, 575-582.

12. Carrara, S.; Bavastrello, V.; Ricci, D.; Stura, E.; Nicolini, C. Improved nanocomposite materials for biosensor applications investigated by electrochemical impedance spectroscopy. Sens. Actuators B 2005, 109, 221-226.

13. Hagen, G.; Dubbe, A.; Rettig, F.; Jerger, A.; Birkhofer, T.; Müller, R.; Plog, C.; Moos, R. Selective impedance based gas sensors for hydrocarbons using ZSM-5 zeolite films with chromium(III) oxide interface. Sens. Actuators B 2006, 119, 441-448.

14. Bisquert, J.; Garcia-Belmonte, G.; Bueno, P.; Longo, E.; Bulhoes, L.O.S. Impedance of constant phase element (CPE)-blocked diffusion in film electrodes. J. Electroanal. Chem. 1998, 452, 229-234.

15. Bisquert, J.; Belmonte, G.G.; Fabregat-Santiago, F.; Bueno, P.R. Theoretical models for ac impedance of finite diffusion layers exhibiting low frequency dispersion. J. Electroanal. Chem. 1999, 475, 152-165.

16. Savage, N.O.; Akbar, S.A.; Dutta, P.K. Titanium dioxide based high temperature carbon monoxide selective sensor. Sens. Actuators B 2001, 72, 239-248.

17. Ward, M.R. Electrical Engineering Science; McGraw-Hill Book Co., New York City, NY, USA, 1971, pp. 36-40.

18. Avila-Paredes, H.; Choi, K.; Chen, C.T.; Kim, S. Dopant-concentration dependence of grainboundary conductivity in ceria: A space-charge analysis. J. Mater. Chem. 2009, 19, 4837-4842.

19. Guo, X.; Ding, Y. Grain boundary space charge effect in zirconia. J. Electrochem. Soc. 2004, $151, \mathrm{~J} 1-\mathrm{J} 7$.

20. Hagenbeck, R.; Waser, R. Influence of temperature and interface charge on the grainboundary conductivity in acceptor-doped $\mathrm{SrTiO}_{3}$ ceramics. J. Appl. Phys. 1998, 83, 2083-2092.

21. Martin, M. Grain boundary ionic conductivity of yttrium stabilized zirconia as a function of silica content and grain size. Solid State Ionics 2003, 161, 67-79.

22. Kosacki, I.; Anderson, H.U. Nanostructured oxide thin films for gas sensors. Sens. Actuators $B$ 1998, 48, 263-269.

(C) 2014 by the authors; licensee MDPI, Basel, Switzerland. This article is an open access article distributed under the terms and conditions of the Creative Commons Attribution license (http://creativecommons.org/licenses/by/3.0/). 